\title{
Qualidade ambiental em afluente de cabeceira do Rio Paraguai sob influência de agricultura e urbanização
}

Objetivou-se, com este trabalho, investigar a qualidade ambiental da água de um riacho, afluente da margem direita do Rio Paraguai, no perímetro urbano de Barra do Bugres (MT) na confrontação com monocultivo de cana-de-açúcar, na mesorregião sudoeste de Mato Grosso. Realizou-se uma coleta no mês de abril, no trecho lótico, antes da desembocadura no Lago Azul, a qual foi resfriada e preservada e posteriormente enviada para um laboratório certificado, onde fo determinada a concentração de Ferro (Fe), Manganês (Mn), Cádmio (Cd), Chumbo (Pb), Cromo ( $\mathrm{Cr}$ ), Níquel (Ni), Zinco (Zn), Cobre Dissolvido (Cu), Mercúrio ( $\mathrm{Hg}$ ) e Surfactantes (Surf.). Da mesma amostra, tomaram-se medidas do Potencial Hidrogeniônico (pH), Oxigênio Dissolvido (OD), Fósforo Total (PT), Nitrogênio Total (NT), Cálcio (Ca), Magnésio (Mg), Cloretos (Cl), Bicarbonato (BiC), Alcalinidade (Alc), Dureza (Du), Condutividade Elétrica (CE), Sólidos Totais (ST), Turbidez (Tu), Temperatura (T) e Demanda Bioquímica de Oxigênio (DBO), as quais foram determinadas no Laboratório de Qualidade de Água da UNEMAT. Os resultados, para cada variável, foram comparados aos parâmetros da Resolução no 357/2005 do Conselho Nacional de Meio Ambiente (CONAMA). Posteriormente, calculou-se o Índice de Qualidade de Água (IQA), Índice de Estado Trófico baseado no Fósforo (IETP) e o Índice de Manutenção da Vida Aquática (IVA). Observou-se que a água varia entre Ruim e Razoável pelo IQA com IETP Eutrófico e IVA Ruim.

\section{Environmental quality in headwaters tributary of Paraguay River under influence of agriculture and urbanization}

The objective of this work was to investigate the environmental quality of a stream water, tributary of the right bank of the Paraguay River, in the urban perimete of Barra do Bugres (MT) in the confrontation with sugarcane monoculture, in the southwest mesoregion. from Mato Grosso. A collection was carried out in April, in the lot, before the mouth of Lago Azul, which was cooled and preserved and later sent to a certified laboratory, where the concentration of Iron (Fe), Manganese ( $\mathrm{Mn}$ ) was determined. , Cadmium (Cd), Lead (Pb), Chromium (Cr), Nickel (Ni), Zinc ( $\mathrm{Zn}$ ), Dissolved Copper (Cu), Mercury (Hg) and Surfactants (Surf.). From the same sample, measurements were taken of Hydrogen Potential (pH), Dissolved Oxygen (DO), Total Phosphorus (PT), Total Nitrogen (NT), Calcium (Ca), Magnesium (Mg) Chlorides (Cl), Bicarbonate (BiC), Alkalinity (Alc), Hardness (Du), Electrical Conductivity (EC), Total Solids (ST), Turbidity (Tu), Temperature (T) and Biochemical Oxygen Demand (BOD), which were determined in the Laboratory. UNEMAT Water Quality. The results for each variable were compared to the parameters of Resolution No. 357/2005 of the National Environmental Council (CONAMA). Subsequently, the Water Quality Index (WQI), the Phosphorus Based Trophic State Index (IETP) and the Aquatic Life Maintenance Index (VAT) were calculated. Water was found to vary from Poor to Fair by EQI with Eutrophic IET and Poor IVA.

Keywords: Water resource; Sanitation; Pollution; Water quality indices.

Topic: Engenharia Ambiental

Reviewed anonymously in the process of blind peer
Received: 05/10/2018

Approved: 04/11/2018
Tadeu Miranda de Queiroz

Universidade do Estado de Mato Grosso, Brasil

http://lattes.cnpq.br/2582121765769124

tdmqueiroz@yahoo.com.br

\section{Jéssica Ramos de Oliveira}

Universidade do Estado de Mato Grosso, Brasil

http://lattes.cnpq.br/5961662650816768

iessica-r24@hotmail.com

\section{Margarida Marchetto (iD}

Universidade Federal de Mato Grosso, Brasil

http://lattes.cnpq.br/8661520853211077

http://orcid.org/0000-0002-8422-943X

marchetto.ro@gmail.com
Referencing this:

QUEIROZ, T. M.; OLIVEIRA, J. R.; MARCHETTO, M.. Qualidade ambiental em afluente de cabeceira do Rio Paraguai sob influência de agricultura e urbanização. Revista Ibero-Americana de Ciências Ambientais, v.9, n.8, p.82-92, 2018. DOI: http://doi.org/10.6008/CBPC2179-6858.2018.008.0008 


\section{INTRODUÇÃO}

A relação homem e natureza tem causado grandes preocupações nos últimos anos. A pressão sobre áreas produtivas, expansão urbana em áreas verdes e as práticas inadequadas de uso da terra, tem estimulado o desmatamento, a erosão dos solos, poluição ambiental e a degradação dos recursos hídricos, oriundo do uso de defensivos agrícolas, lançamento de efluentes domésticos, e destino incorreto de lixos (OLIVEIRA FILHO et al., 2012, PINTO et al., 2012).

Os efeitos da urbanização e das atividades antropogênicas, combinados com o rápido crescimento populacional, tem demonstrado seus efeitos nos ecossistemas aquáticos, com a degradação de rios, lagos e córregos, especialmente no meio urbano, com a contribuição de esgoto doméstico e industrial, além de sedimentos e resíduos urbanos (FIA et al., 2015).

As características da qualidade da água refletem as condições ambientais da bacia hidrográfica, possibilitando compreender o comportamento ecológico do ecossistema e detectar as interferências antrópicas (SOUZA et al., 2014). O seu estudo é fundamental também para a avaliação das suas possibilidades de utilização (PONTES et al., 2012). Diversos estudos demonstram o impacto das ações antrópicas, especialmente a interferência urbana, nas características naturais de rios, alterando a qualidade das águas (ALBERTONI et al., 2017; GRIECO et al., 2017; FIA et al., 2015; SOUZA et al., 2014; PINTO et al., 2012).

Na década de 1980, com grande migração vinda de Minas Gerais, São Paulo e Ceará, o ciclo econômico de Barra do Bugres e região, foi transformado por investimentos na pecuária e agricultura de cana-de-açúcar. Atualmente as áreas do município foram alteradas através da ampliação do uso e cobertura do solo, aumentando áreas agropecuárias em suas matas ciliares (PESSOA et al., 2014).

A qualidade da água de bacias hidrográficas pode ser afetada por diversos fatores antrópicos ou naturais, como a interação entre estes. Portanto, valores que refletem a qualidade da água devem ser estabelecidos, por meio de monitoramento de variáveis físicas, químicas e biológicas, a fim de acompanhar as condições de qualidade e como esta é afetada pelas atividades antrópicas (PINHEIRO et al., 2014). Estudos das condições e dos níveis de contaminação dos corpos hídricos são importantes instrumentos para o planejamento ambiental, contribuindo e orientando a alteração de procedimentos e políticas públicas na gestão de recursos hídricos (OLIVEIRA FILHO et al., 2012).

O monitoramento de recursos hídricos possibilita a obtenção de dados qualitativos e quantitativos da água, apresentando a qualidade de forma conceitual e generalizada, de acordo com seus possíveis usos (FIA et al., 2015). Quanto a isto, os índices de qualidade da água constituem ferramentas rápidas de avaliação das características hídricas em relação a fontes de poluição, e importantes instrumentos de comunicação com a sociedade sobre temas científicos complexos, contribuindo para o correto manejo e gestão de recursos hídricos (SILVA et al., 2014). Diante do exposto o presente estudo tem como objetivo avaliar a qualidade da água de um riacho sob forte influência urbana e agrícola, a partir de índices de qualidade de água e da Resolução CONAMA 357/2005 para águas de classe 2. 


\section{MATERIAIS E MÉTODOS}

\section{Área de estudo}

O município de Barra do Bugres está localizado a cerca de $150 \mathrm{~km}$ de Cuiabá, a capital do estado de Mato Grosso. O município recebe este nome pela confluência (foz) do Rio Bugres com o Rio Paraguai, local denominado de Barra. O município foi ocupado por volta do século XIX, por conta da exploração de poaia e látex de seringueira. Atualmente, possui cerca de 31 mil habitantes, com densidade demográfica de 5 habitantes por $\mathrm{km}^{2}$ (IBGE, 2010).

O curso d'água que abastece o Lago Azul é formado por duas nascentes principais: uma que está inserida na zona urbana do município de Barra do Bugres (MT), entre os bairros Jardim Terra Nova e Jardim dos Pássaros (A), denominada Cabeceiras e outra na bordadura de uma lavoura de cana-de-açúcar (B), denominada Córrego do Tanque, conforme a figura 1. O curso d'água principal é cortado pela MT-343 e deságua em um lago artificial denominado Lago Azul, o qual serve de mirante de contemplação, além de abrigar nas suas margens uma pista de caminhada e uma academia ao ar livre, demonstrando ser um local bastante frequentado.

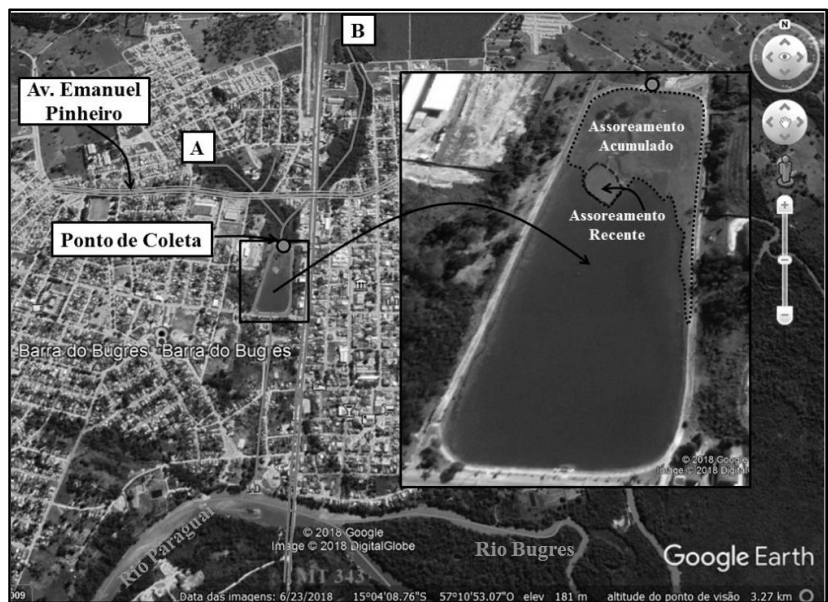

Figura 1: Localização e detalhes do lago azul e seu curso d'água mantenedor.

No cruzamento com a Avenida Emanuel Pinheiro, ambos os cursos d'água são canalizados em manilhas de concreto e seguem enterrados até o ponto onde eles se encontram seguindo dali em diante em canal de concreto até o lago. Neste lago, é comum a presença de capivaras e outros animais silvestres além de peixes oriundos de soltura de alevinos. Não há controle preciso de fuga desses peixes, os quais podem migrar para o rio Paraguai e se misturarem à ictiofauna nativa, estando sujeitos à pesca e uso na alimentação humana. Além disso, embora existam avisos proibitivos (placas), a pesca no lago ocorre esporadicamente de modo clandestino.

\section{Amostragem e análise de água}

Em abril (12/04/18), no final da estação das chuvas (verão/outono) na região, foi feita uma coleta de água no trecho corrente do canal de concreto que conduz alimenta o Lago Azul, antes do deságue. Uma parte dessa amostra foi encaminhada para um laboratório certificado no qual se realizou a determinação dos 
metais pesados Cádmio (Cd), Chumbo (Pb), Cromo (Cr), Níquel (Ni), Zinco (Zn), Cobre Total Dissolvido (Cu) e Mercúrio ( $\mathrm{Hg}$ ) além de Ferro (Fe), Manganês ( $\mathrm{Mn}$ ) e Surfactantes (Surf). Outra parte foi encaminhada ao Laboratório de Qualidade de Água (LaQuA) da Universidade do Estado de Mato Grosso (UNEMAT), no Campus de Barra do Bugres onde analisou-se o Potencial Hidrogeniônico (pH), Oxigênio Dissolvido (OD), Fosfato Total $\left(\mathrm{P}_{\mathrm{T}}\right)$, Nitrogênio Total $\left(\mathrm{N}_{\mathrm{T}}\right)$, Cálcio $(\mathrm{Ca})$, Magnésio $(\mathrm{Mg})$, Cloretos $(\mathrm{Cl})$, Bicarbonato $(\mathrm{BiC})$, Alcalinidade (Alc), Dureza (Du), Condutividade Elétrica (CE), Sólidos Totais (ST), Turbidez (Tu), Temperatura (T) e Demanda Bioquímica de Oxigênio (DBO).

\section{Índices de Qualidade da Água}

De posse dos resultados das análises, calculou-se o Índice de Estado Trófico baseando no fósforo (IETP) para ambientes lóticos seguindo a metodologia de Lamparelli (2004). A determinação do EIT baseado no fósforo tem respaldo em trabalhos atuais, como Ferreira et al. (2014), Silva et al. (2014), entre outros. Calculou-se também do Índice de Qualidade das Águas para Proteção da Vida Aquática e de Comunidades Aquáticas (IVA), admitindo-se o valor 3 para o grupo de Substâncias Essenciais (VE), uma vez que o teste toxidade da água não está disponível no estado de Mato Grosso.

Tal procedimento é considerado adequado (CETESB, 2012), podendo-se calcular o IVA nos casos em que se tenha medidas de pH e OD, admitindo-se que a concentração de OD é menor que $3,00 \mathrm{mg} \cdot \mathrm{L}^{-1}$. Para tanto, considerou-se os valores obtidos nos índices do IETp e do Índice de Variáveis Mínimas para a Preservação da Vida Aquática (IPMCA).

Na ausência da contagem de colônias de Coliformes Termotolerantes (CT) na amostra de água coletada, aplicou-se a concentração máxima obtida na curva de determinação do qi para o cálculo do Índice de Qualidade da Água (IQA). Tal concentração é da ordem de 1 × $10^{5}$ que leva a um qi resultante de 4,91. Esse procedimento foi adotado à semelhança do que é permitido para o IVA substituindo a variável ausente por um valor que maximiza o efeito dela no índice.

Para comparação, também se calculou o IQA, admitindo concentração mínima de $\mathrm{CT}$, resultando em $q_{i}$ igual a 100, mantendo os valores reais das demais variáveis. Por esse procedimento fez-se uma estimativa dos limites máximos e mínimos prováveis para a concentração de coliformes termotolerantes, uma vez que não foi possível fazer a determinação exata. Espera-se com essa aproximação estimar o IQA para o riacho em questão, considerando a importância desse índice de qualidade.

Os resultados foram comparados aos Valores Máximos Permitidos (VMP) para águas doces superficiais de Classe 2 da Resolução CONAMA no 357/2005. As variáveis não citadas na referida resolução foram comparadas com parâmetros de referência da literatura científica atual. Os índices de qualidade tiveram seus valores calculados enquadrados nas faixas de valores, categorizando cada um deles.

Utilizando o software Google Earth Pro foi determinada a área e perímetro do Lago Azul, seguindo seu contorno artificial, a área e perímetro do trecho assoreado total, e área e perímetro da mancha de assoreamento mais recente, determinada por camada exposta de cor semelhante à terra e sem cobertura vegetal. Calcularam-se as proporções de área assoreada absoluta e relativa (\%) à área total do lago. 


\section{RESULTADOS E DISCUSSÃO}

Na tabela 1 apresentam-se os resultados e o Valor Máximo Permitido (VMP), conforme Resolução CONAMA no 357 de 17/03/2005. Pela tabela 1, verifica-se que apenas o Ferro, Fósforo e Turbidez excederam o VMP para águas doces de Classe 2 da Resolução CONAMA no 357/2005. Já para o Manganês o resultado foi igual ao VMP indicando necessidade de atenção em relação a essa substância. As demais variáveis estão em conformidade o com os limites considerados adequados.

Tabela 1: Resultado e parâmetro para cada variável avaliada no riacho do Lago Azul, em Barra do Bugres (MT).

\begin{tabular}{|c|c|c|c|}
\hline Grupo & Variável & Resultado* & Parâmetro** \\
\hline \multirow{2}{*}{ Substâncias Organolépticas } & Ferro (Fe) & 2,29 & 0,30 \\
\hline & Manganês (Mn) & 0,10 & 0,10 \\
\hline \multirow{8}{*}{ Substâncias Tóxicas } & Cádmio (Cd) & $<0,001$ & 0,001 \\
\hline & Chumbo (Pb) & $<0,01$ & 0,01 \\
\hline & Cromo $(\mathrm{Cr})$ & $<0,01$ & 0,010 \\
\hline & Níquel (Ni) & $<0,01$ & 0,025 \\
\hline & Zinco (Zn) & $<0,011$ & 0,180 \\
\hline & Cobre Dissolvido $(\mathrm{Cu})$ & $<0,004$ & 0,009 \\
\hline & Mercúrio $(\mathrm{Hg})$ & $<0,00002$ & 0,0002 \\
\hline & Surfactantes (Surf) & $<0,25$ & - \\
\hline \multirow{2}{*}{$\begin{array}{l}\text { Variáveis } \\
\text { Essenciais }\end{array}$} & $\mathrm{PH}$ & 7,37 & 6,0 a 9,0 \\
\hline & Oxigênio Dissolvido (OD) & 5,61 & $>5,00$ \\
\hline \multirow{4}{*}{ Nutrientes } & Fósforo Total $\left(\mathrm{P}_{\mathrm{T}}\right)$ & 0,168 & 0,10 \\
\hline & Nitrogênio Total $\left(\mathrm{N}_{\mathrm{T}}\right)$ & 0,412 & 10,00 \\
\hline & Cálcio (Ca) & 13,09 & - \\
\hline & Magnésio (Mg) & 6,24 & - \\
\hline \multirow{9}{*}{ Físico-químicas } & Cloretos $(\mathrm{Cl})$ & 8,92 & 250,00 \\
\hline & Bicarbonato (BiC) & 57,94 & - \\
\hline & Alcalinidade (Alc) & 56,07 & - \\
\hline & Dureza (Du) & 58,33 & - \\
\hline & Condutividade Elétrica (CE) & 186,59 & - \\
\hline & Sólidos Totais (ST) & 177,00 & 500,00 \\
\hline & Turbidez (Tu) & 155,00 & 100,00 \\
\hline & Temperatura $(T)$ & 29,00 & - \\
\hline & DBO & 4,82 & $<5,00$ \\
\hline
\end{tabular}

Legenda: *Resultado em mg L $\mathrm{L}^{-1}$, exceto $\mathrm{pH}$, Condutividade Elétrica $\left(\mu \mathrm{S} . \mathrm{cm}^{-1}\right)$, Turbidez (UNT), Temperatura $\left({ }^{\circ} \mathrm{C}\right)$.

**Resolução № 357/2005-CONAMA - Classe II.

O ferro é um elemento rico na natureza, encontrado comumente em rochas e solos. Sua presença em bacias hidrográficas se deve principalmente pela ação do intemperismo das rochas e da erosão de solos em abundância deste elemento (OLIVEIRA FILHO et al., 2012). Sendo assim, a elevada concentração de Ferro na água pode estar relacionada com prováveis carreamentos de solo devido a processos erosivos, e do assoreamento observados no riacho. Assim como o ferro, o manganês também está presente em águas superficiais devido a processos naturais de erosão de minerais, como também reações de oxirredução quando há interação entre os sedimentos e água, ocasionando a liberação de Manganês na água (GRIECO et al., 2017). Portanto, a concentração de Manganês relaciona-se a causas geogênicas.

Contudo, no estudo encontraram-se quantidades de Mn próximas ao máximo permitido, revelando preocupações quanto a este elemento na água, pois de acordo com Dieter et al. (2005), altas concentrações de Mn na água podem ser a causa de doenças neurológicas, desenvolvidas pela ação tóxica que destrói os mecanismos neurológicos, causando doenças como manganismo e mal de Alzheimer. Sendo assim, a água do riacho não é indicada para abastecimento humano, sem prévio tratamento adequado. No entanto, foi 
constatado que parte da população circunvizinha ao córrego faz uso da água para consumo e atividades domésticas, se expondo a um problema de saúde pública.

Todas as variáveis do grupo de substâncias tóxicas apresentaram-se abaixo dos valores máximos permitidos para águas doces de classe 2 conforme a Resolução № 357/2005. A região estudada é caracterizada sob forte urbanização, localizada próximo a estradas as quais passam grande quantidade de carros e caminhões que lançam fumaça pelo escapamento, a qual pode se depositar as margens do riacho e se incorporar às águas.

Próximo às margens do riacho também há oficinas mecânicas e lava-jatos que lançam seus resíduos ao córrego, contendo também uma de suas nascentes presente em uma área agrícola. Conforme Souza et al. (2014) a presença de metais pesados na água provém de ações antropogênicas, geralmente de atividades agrícolas, encontrado mais comumente em bacias hidrográficas com interferências antrópicas. As baixas concentrações de substâncias tóxicas indicam bons resultados, contudo ele requer atenção e cuidado, pois possui alta propensão a contaminação.

O grupo de variáveis essenciais também se apresentou dentro dos limites exigidos para águas de classe 2. No entanto, o valor encontrado para Oxigênio Dissolvido está próximo ao limite recomendado, indicando que se deve atentar quanto a qualidade da água do riacho, pois baixos valores de OD podem indicar contaminação por esgoto urbano e industrial e de resíduos agropecuários. A alta carga de matéria orgânica também contribui para a diminuição de oxigênio, causando mortandade de peixes sensíveis a este tipo de variação (BLUME et al., 2010).

O estudo de Souza et al. (2014) comprova que em bacias urbanas com maior número de habitantes há menores concentrações de OD, indicando como fonte potencial de poluição a descarga de efluente doméstico. O riacho do Lago Azul pode estar recebendo lançamentos de esgoto clandestinos, podendo este fator estar contribuindo para a diminuição de oxigênio na água futuramente. Quanto aos nutrientes, apenas o fósforo excedeu o limite indicado pela Resolução CONAMA no 357/2005. As altas quantidades de Fósforo na água indicam fonte de poluição urbana e agrícola. O estudo de Albertoni (2017) e Souza et al. (2014) evidenciou esta relação por meio da obtenção de valores maiores de fósforo em bacias com maior interferência urbana, pela descarga de esgoto doméstico, e rural pela lixiviação de insumos agrícolas.

A deterioração da qualidade da água do riacho, quanto ao fósforo, pode estar relacionada aos lançamentos indevidos de esgotos domésticos e de empresas localizadas próximo ao córrego, como também ao escoamento superficial nas áreas rurais, contribuindo para o carreamento de insumos agrícolas para a água, este último fator seria minimizado se a população tivesse o hábito de manter a área de preservação permanente - APP e se não lançassem esgoto in natura e lixo aos nos corpos d'água.

Os elementos cálcio e magnésio não possuem limites estabelecidos nas legislações vigentes; contudo, conforme Queiroz et al. (2018), baixos níveis de cálcio podem causar doenças como osteoporose, hipertensão, acidente vascular cerebral, dentre outras, cuja principal fonte deste mineral é a água. Queiroz et al. (2018) também ressaltam a quantidade de Magnésio na água que é capaz de trazer malefícios a saúde (>250 mg $\left.\cdot \mathrm{L}^{-1}\right)$, como o efeito laxativo. 
Sendo assim, a água do riacho pode ser utilizada para o consumo humano sem causar prejuízos à saúde, conforme a concentração de Magnésio. Lembrando que águas com classificação 2, só podem ser consumidas para abastecimento, após tratamento completo. A Resolução CONAMA no 357/2005 está relacionada a águas superficiais e suas classificações. Quando se trata de água para abastecimento humano se deve seguir a Portaria do Ministério da Saúde (MS).

Dentre as variáveis físico-químicas presentes na Resolução no 357/2005 do CONAMA, a Turbidez apresentou-se superior ao indicado para águas de classe 2. Este resultado pode estar associado aos eventos de erosão, haja vista os processos de assoreamento já observados no riacho e ainda mais intensificados pela ocorrência de chuvas, período em que ocorreu a coleta, que favorecem o transporte de sólidos para a água, comumente observados em áreas de uso do solo agrícola (QUEIROZ et al., 2018; SOUZA et al.; 2014), como também a lançamentos de esgotos com alta carga de material em suspensão (GRIECO et al., 2017).

Verificou-se também que o valor de DBO esteve muito próximo ao limite exigido, demonstrando que esta variável requer atenção no riacho. O estudo de Blume et al. (2010) verificou maiores concentrações de DBO em local com liberação de esgoto não tratado, indicando a fonte de contaminação por matéria orgânica no Rio dos Sinos (RS). O estudo de Fia et al. (2015) também relaciona atividades com alta carga de poluição por matéria orgânica com elevações nos valores de DBO. Portanto, devem-se sugerir possíveis fontes de contaminação orgânica, que podem interferir nos aspectos qualitativos da água do riacho.

As concentrações de Bicarbonatos na água não são consideradas nas legislações vigentes, contudo para irrigação é indicado valores abaixo de $1,5 \mathrm{mmol}_{c} \cdot \mathrm{L}^{-1}$ para que não haja restrições em seu uso (AYERS et al., 1999). Sendo assim, a água do riacho pode ser utilizada na irrigação, haja vista os valores de Bicarbonatos serem $1,42 \mathrm{mmol}_{\mathrm{c}} \cdot \mathrm{L}^{-1}$, contudo requer atenção, pois o valor encontrado é muito próximo ao limite de restrição.

A alcalinidade da água é abordada pela Fundação Nacional de Saúde (FUNASA, 2009), indicando os valores de 30 a $500 \mathrm{mg} \cdot \mathrm{L}^{-1}$ em uma faixa considerada normal. Sendo assim, a água do riacho pode ser considerada normal. Contudo, de acordo com Pinheiro et al. (2014), valores elevados de alcalinidade, como observado no presente estudo, associam-se a processos de decomposição de matéria orgânica e de liberação e dissolução de gás carbônico, oriundo da respiração dos micro-organismos. Sendo assim, o valor encontrado no presente estudo pode estar indicando o alto grau de interferência antrópica na qualidade da água do riacho.

Quanto à dureza, a Portaria no 05 do Ministério da Saúde (BRASIL, 2017), indica para abastecimento público valores inferiores a $500 \mathrm{mg} \cdot \mathrm{L}^{-1}$, assim a água do riacho se enquadra dentro dos limites, classificada como uma água mole ( 0 a $\left.55 \mathrm{mg} \cdot \mathrm{L}^{-1}\right)$. A Condutividade Elétrica apresentou um valor elevado, superior ao limite considerado normal pela Companhia Ambiental do Estado de São Paulo (CETESB, 2009) de 100 $\mu$ S.cm${ }^{1}$, indicando a presença de grande quantidade de íons dissolvidos na água. Valores elevados de Condutividade Elétrica podem relacionar-se com ambientes poluídos por esgotos domésticos ou industriais (BRASIL, 2014), revelando que o riacho pode estar sendo poluído por efluentes que estão interferindo na condutividade elétrica. 


\section{Índices de qualidade da água}

Na determinação do IPMCA, tanto as variáveis do grupo de Substâncias Tóxicas (SE), quanto as Variáveis Essenciais (VE), enquadram-se no nível A convergindo para categoria 1. Devido à ausência do teste toxidade do grupo de SE a categoria desse grupo, foi progredida de 1 para 3, conforme recomendação da CETESB (2012). Por esse provimento o valor do IPMCA calculado foi de 3, considerado 'Ruim' (categorias 3 e 4). Os resultados indicam que o riacho pode conter alta carga de contaminação capaz de interferir nas variáveis mínimas para a manutenção da vida aquática, e caso não haja mudanças quanto a redução poluição a vida aquática pode ser reduzida, ou até mesmo eliminada.

O IET calculado com base na concentração de fósforo é de 60,55, classificado como Eutrófico $(59<$ IET<63), o qual se enquadra na categoria 3, caracterizado por alta produtividade de nutrientes em condições normais, águas com transparência reduzida, causando interferências na qualidade da água e em seus múltiplos usos (CETESB, 2012). Este resultado já era esperado, pois é possível observar próximo ao ponto de coleta águas de coloração esverdeada, que indicam um estado de eutrofização. A eutrofização gera a diminuição da transparência da água, tornando-a turva, como também a diminuição do oxigênio dissolvido, causando a morte de peixes sensíveis (PINTO et al., 2012; BLUME et al., 2010).

O nível trófico elevado pode estar relacionado com interferências agrícolas, haja vista uma das nascentes estar presente em uma área destinada ao monocultivo de cana-de-açúcar, e através do escoamento superficial proveniente da chuva, insumos agrícolas ricos em nutrientes podem ter sido carreados para o leito do riacho, favorecendo o aumento do nível trófico. Situação semelhante foi observada no estudo de Albertoni et al. (2017) no Canal de São Gonçalo (RS) em que obteve resultados de águas altamente eutrofizadas no período de chuvas, com classificação Supereutrófica.

Este valor elevado, segundo Albertoni et al. (2017), deu-se por conta de a bacia estar localizada próximo a plantações de arroz, em que no período de chuva as culturas são esgotadas e a água de irrigação é devolvida aos rios, enriquecendo os corpos d'água através de insumos agrícolas dissolvidos. Os esgotos domésticos também podem favorecer os aumentos do no nível trófico de um rio, como observado no estudo de Fia et al. (2015). O riacho do Lago Azul está localizado em uma área urbanizada em que possíveis descargas de esgotos urbanos e domésticos podem estar contribuindo para o aumento da concentração de nutrientes.

O IVA tem o objetivo de avaliar a qualidade das águas com fins de proteção da fauna e flora aquática, considerando a presença e a concentração de contaminantes químicos tóxicos e seus efeitos sobre os organismos aquáticos, como também variáveis essenciais para a biota, presentes nos índices IPMCA e IET, fornecendo informações sobre a qualidade da água em termos ecotoxicológicos e sobre níveis de trofia (CETESB, 2012). Com base nos valores do IETp e do IPMCA foi calculado o IVA, o qual tem valor de 6,6, classificando a água como 'Ruim' $(4,6 \leq$ IVA $\leq 6,7)$ para a proteção da vida aquática.

O resultado obtido para o IVA no riacho do Lago Azul revela a qualidade inferior da água do córrego, indicando que as fontes de poluição pontuais e difusas, esgotos comerciais, domésticos e agrícolas, possuem alta carga de contaminação, capazes de alterar ou até eliminar a vida aquática do córrego. $O$ estudo de 
Frinhani et al. (2010) constatou que rios em áreas rurais com despejo de efluente de suínos obtiveram índice de qualidade da água para a proteção da vida aquática melhor que em áreas urbanas que recebem lançamento de esgoto doméstico in natura, demonstrando que a disposição final dos dejetos suínos foi realizada de maneira adequada, enquanto os esgotos domésticos não teve nenhum tratamento, tendo seu potencial poluidor acentuado.

Vale destacar que a vazão do corpo receptor determina a qualidade da mistura, ao receber o efluente, rios caudalosos não sofrem muito a influência de pequenas cargas de esgoto, seja esgoto doméstico ou não. Ressalta-se também que efluentes de suinocultura possuem cargas orgânicas superiores ao esgoto doméstico.

O estudo de Silva et al. (2014) também obteve qualidade de água inferior para manter a vida aquática do Rio Anil e um afluente do Rio Bacanga (MA), devido ao lançamento de esgoto doméstico in natura. $\mathrm{O}$ lançamento de efluentes in natura aos corpos hídricos causa, além de impactos socioambientais, causam impactos negativos no meio ambiente em geral e na vida aquática, como o excesso de matéria orgânica que diminui o oxigênio dissolvido, levando à morte de organismos aeróbios, como também a eutrofização, a veiculação de doenças hídricas pelas presença de bactérias, desequilíbrio ecológico, problemas de escassez hídrica, dentre outros (FRINHANI et al., 2010).

O IQA calculado, considerando o valor máximo possível para Coliformes Termotolerantes, foi de 41,95, classificado como 'Ruim' ( $26 \leq$ IQA $\leq 50)$. Quando se lançou na equação do IQA a concentração mínima de CT igual a 1 obteve-se um IQA de 67,53, o qual se enquadra na categoria de águas Razoáveis. Diante desse resultado, verifica-se que a qualidade da água do riacho, pelo IQA, provavelmente esteja entre Razoável e Ruim. Resultado semelhante foi observado no estudo de Barros et al. (2011), córrego André em Mirassol D’Oeste (MT), em que se obteve um IQA classificado como 'Razoável'. Esta classificação evidenciou a interferência antrópica no córrego devido aos efluentes domésticos, comerciais e agropecuários.

O IQA encontrado no presente estudo reflete as atividades antrópicas, por ser um córrego urbano, sofre com a poluição e contaminação de efluentes comerciais e possíveis esgotos domésticos, além das contribuições oriundas das atividades agrícolas próximo a nascente. O estudo de Pontes et al. (2012) encontrou IQA classificado como 'Ruim' em áreas com residências na microbacia do Córrego do Banguelo $(\mathrm{MG})$, indicando que áreas urbanas contribuem para a deterioração da qualidade da água. O IQA é um importante instrumento de monitoramento da qualidade da água, que contribui como uma ferramenta de auxílio para a gestão ambiental e a tomada de decisão de órgãos públicos (PINTO et al., 2012).

\section{Assoreamento do Lago Azul}

A mancha recente apresenta coloração avermelhada, típica de terra, sem cobertura vegetal, além de se localizar na porção central do lago no final da linha d'água corrente (figura 1), sugerindo tratar-se de deposição de sedimentos transportados na última estação de chuvas. A data da imagem é 23/06/2018, ou seja, 2 meses e meio após as coletas. Observa-se, através da tabela 2, que o lago já possui 27,04\% da sua superfície assoreada. Analisando o tamanho da superfície de assoreamento recente (2,13\%) deduz-se que o 
processo de assoreamento é antigo, podendo-se estimar um período aproximado de 13 anos de acúmulo de sedimentos. Admitindo uma taxa de assoreamento de 2,13\% por ano, a cada estação chuvosa, estima-se que num período 34 anos o lago poderá ser extinto se nada for feito.

Tabela 2: Área e perímetro do lago e das manchas de assoreamento.

\begin{tabular}{|l|c|c|c|}
\hline \multicolumn{1}{|c|}{ Variável } & Perímetro $(\mathrm{m})$ & Área $\left(\mathrm{m}^{2}\right)$ & Área Relativa $(\%)$ \\
\hline Lago Azul & 778,10 & $33.459,19$ & $100 \%$ \\
\hline Assoreamento total & 519,61 & $9.045,08$ & $27,04 \%$ \\
\hline Assoreamento recente & 101,76 & 711,39 & $2,13 \%$ \\
\hline
\end{tabular}

Xavier et al. (2010) destaca que as alterações no uso do solo têm gerado uma das mais graves formas de degradação da paisagem, a erosão, e as atividades antrópicas tem acelerado estes processos. Xavier et al. (2010) ainda ressalta que os impactos diretos dos processos erosivos é o aumento da produção de sedimentos, estes ao atingirem corpos hídricos podem gerar o assoreamento, além de contribuir no transporte de poluentes.

\section{CONCLUSÕES}

As análises demonstraram que apenas as variáveis de Ferro, Fósforo total e Turbidez se apresentaram acima do limite máximo estabelecido pela Resolução CONAMA no 357/2005 para águas de classe 2 . O riacho apresentou qualidade adequada conforme as demais variáveis. Embora o riacho apresente variáveis em conformidade, deve-se atentar às suas características qualitativas no futuro, se as autoridades não intervirem com saneamento básico, pois está localizada em uma área de alto potencial poluidor.

O IPMCA indicou uma água de qualidade classificada como 'Ruim' para a manutenção da vida aquática. O IET revelou uma água classificada como 'Eutrófica', com alta produtividade de nutrientes interferindo os seus múltiplos usos. O IVA sinalizou que a água do riacho é classificada como 'Ruim' para a proteção da fauna e flora aquática. O IQA classificou a água do riacho entre Razoável e Ruim, indicando a alta carga de contaminação das águas. O lago sofre com assoreamento, com 27,04\% de sua superfície já assoreada, com taxa de assoreamento de $2,13 \%$ na estação chuvosa. Embora tenha sido feita uma única amostragem, pode-se inferir que na data da coleta a qualidade da água do lago está comprometida pela ação antrópica. Isso implica que se deve agir no sentido de se preservar os corpos hídricos.

\section{REFERÊNCIAS}

ALBERTONI, E. F.; PALMA-SILVA, C.; TRINDADE, C. R.; FURLANETTO, L. M.. Water quality of the São Gonçalo channel, urban and agricultural water supply in southern Brazil. Revista Brasileira de Recursos Hídricos, v.22, n.2, 2017. DOI: http://doi.org/10.1590/2318-0331.011716082

AYRES, R. S.; WESTCOT, D. W.. A qualidade da água na agricultura. 2 ed. Campina Grande: UFPB, 1999.

BARROS, R. V. G.; SOUZA, H. M. L.; SOUZA, C. A..

Determinação do índice de qualidade da água (IQA) na subbacia do Córrego André em Mirassol D’oeste, Mato Grosso.

Engenharia Ambiental: Pesquisa e Tecnologia, v.8, n.3, p.138-153, 2011.
BLUME, K. K.; MACEDO, J. C.; MENEGUZZI, A.; SILVA, L. B.; QUEVEDO, D. M.; RODRIGUES, M. A. S.. Water quality assessment of the Sinos river, southern Brazil. Brazilian Journal of Biology, v.70, n.4, p.1185-1193, 2010.

BRASIL. Ministério da Saúde. Manual de controle da qualidade da água para técnicos que trabalham em ETAS. Brasília: MS, 2014.

BRASIL. Portaria de Consolidação PRC n.5 de 28 de setembro de 2017. Brasília: DOU, 2017. 
CETESB. Companhia Ambiental do Estado de São Paulo. Índices de Qualidade das Águas. São Paulo: CETESB, 2012.

CETESB. Companhia Ambiental do Estado de São Paulo. Qualidade das águas interiores no estado de São Paulo. São Paulo: CETESB, 2009.

DIETER, H. H.; BAYER, T. A.; MULTHAUP, G.. Environmental Copper and Manganese in the Pathophysiology of Neurologic Diseases (Alzheimer's Disease and Manganism). Acta Hydrochimica et Hydrobiologica, v.33, n.1, p.72-78, 2005. DOI: http://doi.org/10.1002/aheh.200400556

FERREIRA, P. M. L.; QUEIROZ, M. M. F.; COSTA, F. F.; MEDEIROS, M. C.; GARRIDO, F. W. A.. Determinação do Índice De Estado Trófico para fósforo das águas do Rio Piancó Piranhas Açu no Município de Pombal - PB. Revista Verde, v.9, n.4, p.95-101, 2014.

FIA, R.; TADEU, H. C.; MENEZES, J. P. C.; FIA, F. R. L.; OLIVEIRA, L. F. C.. Qualidade da água de um ecossistema lótico urbano. Revista Brasileira de Recursos Hídricos, v.20, n.1, p.267-275, 2015. DOI:

http://doi.org/10.21168/rbrh.v20n1.p267-275

FRINHANI, E. M. D.; CARVALHO, E. F.. Monitoramento da qualidade das águas do Rio do Tigre, Joaçaba, SC. Revista Unoesc \& Ciência, v.1, n.1, p.49-58, 2010.

FUNASA. Fundação Nacional de Saúde. Manual prático de análise de água. 3 ed. Brasília: FUNASA, 2009.

GRIECO, A. A.; FREGONESI, B. M.; TONANI, K. A. A.; SILVA, T. V.; CELERE, B. S.; TREVILATO, T. M. B.; MUÑOZ, S. I. S.; ALVES, R. I. S.. Diagnóstico espacial e temporal de condições físico-químicas e microbiológicas do Córrego do Tanquinho, Ribeirão Preto, SP, Brasil. Revista Ambiente e Água, v.12, n.2, p.282-298, 2017. DOI: http://doi.org/10.4136/1980$\underline{993 X}$

IBGE. Instituto Brasileiro de Geografia e Estatística. Censo 2010. Rio de Janeiro: IBGE, 2018.

LAMPARELLI, M. C.. Graus de Trofia em Corpos d'água do Estado de São Paulo: Avaliação dos métodos de monitoramento. Tese (Doutorado em Ecologia Aplicada) Universidade de São Paulo, São Paulo, 2004.
OLIVEIRA FILHO, P. C.; DUTRA, A. M.; CERUTI, F. C.. Qualidade das Águas Superficiais e o Uso da Terra: Estudo de Caso Pontual em Bacia Hidrográfica do Oeste do Paraná. Revista Floresta e Ambiente, v.19, n.1, p.32-43, 2012. DOI: http://doi.org/10.4322/floram.2012.005

PESSOA, S. P. M.; GALVANIN, E. A. S.; NEVES, S. M. A. S.. Mapeamento do uso e ocupação da floresta aluvial no Rio Paraguai - Barra do Bugres/Mato Grosso. Revista Brasileira de Cartografia, v.66, n.6, p.1295-1303, 2014.

PINHEIRO, A.; SCHOEN, C.; SCHULTZ, J.; HEINZ, K. G. H.; PINHEIRO, I. G.; DESCHAMPS, F. C.. Relação entre o uso do solo e a qualidade da água em bacia hidrográfica rural no bioma Mata Atlântica. Revista Brasileira de Recursos Hídricos, v.19, n.3, p.127-139, 2014

PINTO, L. V. A.; ROMA, T. N.; BALIEIRO, K. R. C.. Avaliação qualitativa da água de nascentes com diferentes usos do solo em seu entorno. Cerne, v.18, n.3, p.495-505, 2012.

PONTES, P. P.; MARQUES, A. R.; MARQUES, G. F.. Efeito do uso e ocupação do solo na qualidade da água na micro-bacia do Córrego Banguelo - Contagem. Ambiente e Água, Taubaté, v.7, n.3, p.183-194, 2012. DOI http://doi.org/10.4136/1980-993X

SILVA, G. S.; SANTOS, E. A.; CORRÊA, L. B.; BRANDES, A. L. M.; MARQUES, E. P.; SOUSA, E. R.; SILVA, G. S.. Avaliação integrada da qualidade de águas superficiais: grau de trofia e proteção da vida aquática nos rios Anil e Bacanga, São Luís (MA). Engenharia Sanitária Ambiental, v.19, n.3, p.245-250, 2014. DOI: http://doi.org/10.1590/S141341522014019000000438

SOUZA, M. M.; GASTALDINI, M. C. C.. Avaliação da qualidade da água em bacias hidrográficas com diferentes impactos antrópicos. Engenharia Sanitária e Ambiental, v.19, n.3, 2014. DOI: http://doi.org/10.1590/S141341522014019000001097

XAVIER, F. V.; CUNHA, K. L.; SILVEIRA, A.; SALOMÃO, F. X. T. Análise da suscetibilidade à erosão laminar na bacia do Rio Manso, Chapada dos Guimarães, MT, utilizando sistemas de informações geográficas. Revista Brasileira de Geomorfologia, v.11, n.2, p.51-60, 2010.

A CBPC - Companhia Brasileira de Produção Científica (CNPJ: 11.221.422/0001-03) detém os direitos materiais desta publicação. Os direitos referem-se à publicação do trabalho em qualquer parte do mundo, incluindo os direitos às renovações, expansões e disseminações da contribuição, bem como outros direitos subsidiários. Todos os trabalhos publicados eletronicamente poderão posteriormente ser publicados em coletâneas impressas sob coordenação da Sustenere Publishing, da Companhia Brasileira de Produção Científica e seus parceiros autorizados. Os (as) autores (as) preservam os direitos autorais, mas não têm permissão para a publicação da contribuição em outro meio, impresso ou digital, em português ou em tradução. 